Latifian, E., Y.E. Arvas, and Y. Kaya, Tagetes minuta Bitkisinin Mikro Üretimi Üzerine Farkl1 BAP ve IAA Konsantrasyonlarının Etkileri. International Journal of Life Sciences and Biotechnology, 2018. 1(2): p. 96-104.

\title{
Tagetes minuta Bitkisinin Mikro Üretimi Üzerine Farklı BAP ve IAA Konsantrasyonlarının Etkileri
}

\author{
EInaz Latifian', Yunus Emre Arvas², Yilmaz Kaya ${ }^{3}$
}

Özet: Tagetes minuta, Asteraceae familyasından tek yıllık, dik olarak gelişen ve 2 metreye kadar boylanabilen otsu bir bitkidir. Bitkinin anavatanı Güney Amerika'dır. Günümüzde tıbbi ve aromatik amaçlı kullanılmakla beraber kurutulmuş yaprakları, çorba, et ve salatalara tat-aroma katmak, insektisit, oda kokusu gibi birçok farklı kullanım alanına sahiptir. Bu çalıșma Tagetes minuta bitkisinin in vitro ortamda doku kültürü parametrelerinin belirlenmesi amacıyla Ondokuz Mayıs Üniversitesi Ziraat Fakültesi Tarımsal Biyoteknoloji Bölümü laboratuvarlarında gerçekleştirilmiştir. Bitki doku kültürü ana materyali olan tohumlar Tarla Bitkileri Bölümü çeşit bahçesinden alınmıştır. İlk önce olgunlaşmış tohumlara yüzey sterilizasyon optimizasyonu uygulanmıştır. Daha sonra steril hale getirilen tohumlar doku kültürü kabininde, içerisinde bitki büyüme düzenleyicisi içermeyen Murashige ve Skoog (MS) besi ortamına ekilmiştir. Ardından 2 gün karanlık ortamda, 8 gün iklim dolabında $18-25{ }^{\circ} \mathrm{C}$ 'de tutulmuştur. Bu ortamda gelişen bitkilerden alınan eksplantlar, farklı konsantrasyonlarda indol asetik asit (IAA) ve benzilaminopurin (BAP) içeren ortamlara konulmuş ve en ideal bitki rejenerasyon optimizasyonu veren ortam belirlenmiştir. Eksplant kaynağı olarak in vitro ortamda yetiştirilen bitkiden elde edilen hipokotil eksplantlar kullanılmıştır. Eksplantlar farklı konsantrasyon ve kombinasyonlarda BAP ve IAA içeren MS besin ortamlarında kültüre alınmıştır. En ideal besi ortamının denendiği araştırmada, in vitro koşullarda bitki rejenerasyonu, rejenerasyon yüzdesi ve kallus oranı incelenmiştir. Yapılan istatistiksel analizler sonucunda farklı bitki büyüme düzenleyicisi konstrasyonları ile eksplant kaynaklarının, bitkinin rejenerasyonuna etkisi olduğu gözlenmiştir.

Anahtar Kelimeler: Tagetes minuta, IAA, BAP, Mikro üretimi

\section{Effects of Different BAP and IAA Concentrations on Micropropagation of Tagetes minuta Plant}

\begin{abstract}
Tagetes minuta is a plant from Asteraceae family that it is annual, herbaceous plant, erect and grow to 2 metres. Nowadays it is used for medicinal and aromatic purposes, dried leaves are used in soup. Also it is used as insecticide and room odor. This study is carried out in Agricultural Biotechnology Lab in Faculty Of Agriculture of University of Ondokuz May1s with the object of the study was to determined the tissue culture parameters of Tagetes minuta. The seeds that it is parent material for plant tissue culture was obtained from variety field of application in Department of Field Crops. Firstly matured seeds of Marigold were applied to surface sterilized and then the seeds that it is sterilized cultured into hormone-free Murashige ve Skoog (MS) medium in petri. The seeds were keeped dark for 2 days and keeped climate chamber for 8 days. After that the explants transferred MS medium supplemented with different concentration of indole acetic acid (IAA) and benzylaminopurine (BAP). Besides that the best medium of regeneration optimization was determined for plant. The source of explants is Hypocotyl. This study investigated the ideal explant source and best dose of growth media for the plant. The plant regeneraiton frequency and explant source was determined in several of plant growth hormone. Results of statistical analysis showed that different hormone concentrations and sources of explant had effect on regeneraiton of the plant in vitro condition.

Keywords: Tagetes minuta, IAA, BAP, Micropropagation
\end{abstract}

\footnotetext{
${ }^{1}$ Ondokuz Mayıs Üniversitesi, Fen Bilimleri Enstitüsü, Tarla Bitkileri Anabilim Dalı, Samsun- Türkiye ${ }^{2}$ Yıldız Teknik Üniversitesi, Fen Bilimleri Enstitüsü, Moleküler Biyoloji ve Genetik Anabilim Dalı, İstanbul- Türkiye

${ }^{3}$ Ondokuz Mayıs Üniversitesi Ziraat Fakültesi Tarımsal Biyoteknoloji Anabilim Dalı, Samsun- Türkiye.

*Sorumlu yazar: yilmaz.kaya@omu.edu.tr
} 


\section{Giriş}

Tagetes minuta, Asteraceae ailesine ait Tagetes genusunun çok önemli bir üyesidir. Küçük çiçekleri ile oldukça dikkat çekici bir kokuya sahiptir. Ilıman iklim kuşağına uyum sağlamaktadır. T. minuta tohumla üretilir [1] ve geleneksel olarak gastrit, hazımsızlık, bağırsak solucanları, deri iltihapları ve hemoroit tedavisinde kullanılmaktadır. Aynı zamanda yeni ilaç bileşikleri için bir kaynak niteliğinde olup bitkisel ilaçların hazırlanması, özellikle kırsal alanda, insanlar ve hayvanlar için geleneksel ilaç üretmede önemli bir kaynaktır [2]. Bunlarla birlikte, Tagetes erecta gibi bazı tagetes türleri ise biyolojik ajan olarak zararlılara karşı doğal mücadelede kullanılabilmekte [3] ve çeşitlerinin gün uzunluğuna tepkileri birbirinden oldukça farklılık göstermektedir [4].

Geleneksel tıbbi bitkilerin genetik biyoçeşitliliği ve büyüme ortamlarının kaybedilmesi, tıbbi bitkilerin denetlenmeyen ticareti nedeniyle sürekli tehdit altındadır. Bu durum birçok tıbbi aromatik bitkiyi doğada tükenme noktasına getirmektedir. Doku kültürü gibi biyoteknolojik yöntemler sayesinde bitki mikroçoğaltımı yapılarak soyu tükenme tehlikesi altında bulunan türler için önlemler alınması gerekmektedir [5]. Genel olarak bitki doku kültürü yöntemi; yeni bitki varyetelerinin üretilmesi, haploid bitki üretimi, germplazm muhafazası, nadir ve tükenmekte olan bitkilerin koruma altına alınması, sekonder metabolitlerin üretilmesi, transgenik bitkilerin elde edilmesi ve çoğaltımı zor olan bitkilerin çoğaltılması amaçları ile uygulanmaktadır [6-8]. Çoğaltma işleminin mevsimden bağımsız olarak uygulanabilmesi, kısa sürede çok sayıda bitki elde edilmesi, in vitro üretilen bitkilerin mikroorganizma kaynaklı hastalıklardan bağımsız olması ve değerli genotiplerin bitki virüslerinden korunabilmesi bitki doku kültürü yönteminin avantajlarıdır [9]. Aynı zamanda bitki doku kültürü yöntemi ile bitkilerin uzun süre stoklarının oluşturulabilmesi mümkündür. Alt kültüre alma işlemi ile kısa ve orta vadede 
bitki depolanabilir ve muhafazası sağlanır [10]. Doku kültürü yöntemiyle çoğaltılan bitkiler doğal habitatlarında yaşayan bitkilere göre daha kontrollü bir kimyasal ve fiziksel çevreye sahiptirler. Böylece büyüme ve gelişmenin her safhası kolayca gözlemlenir ve istenilen dönemde müdahale edilerek çalışmalara yön verilebilir [11]. Doğal yöntemlere kıyasla in vitro mikro çoğaltım tekniğinin geliştirilmesi $T$. minuta bitkisi için daha hızlı şekilde klonal çoğaltım sağlaması bakımından önemlidir. Bu araştırmanın temel amacı tıbbi aromatik ve endüstriyel bitkilerden olan $T$. minuta'nın bitki doku kültürü için en uygun besi ortamı ve bitki büyüme düzenleyicileri içeriğinin in vitro şartlarda belirlenmesidir.

\section{Materyal ve Yöntem}

\section{Bitki materyali}

Çalışmada kullanılan T. minuta bitkisi doğal yayılış alanlarından toplanarak Ondokuz Mayıs Üniversitesi Ziraat Fakültesi, Tarla bitkileri bölümü, tıbbi aromatik bitkiler çeşit bahçesinde yetiştirilen bitkilerin tohumlarıdır.

\section{Yöntem}

Bitki doku kültürü ana materyalleri olan tohumlara ilk önce yüzey sterilizasyon optimizasyonu uygulanmıştır. Daha sonra sırasıyla; tohum yüzey sterilizasyonu, steril kabin içerisinde gerçekleştirilmiştir. Tohumlar sodyum hipoklorit çözeltisinde $15 \mathrm{dk}$. bekletilmiş daha sonra 3'er kez saf sudan geçirilmiştir. Her tekrarda 3 dakika bekletilmiştir. Elde edilen tohumlar \%70 etil alkolde 10 saniye bekletilmiş daha sonra 4'er kez saf sudan geçirilmiş, her tekrarda 5 dakika bekletilmiştir. 2 kez sterile edilen kurutma kâğıdında kurutulmuştur. Steril kuru tohumlar daha önceden hazırlanan MS besi ortamına ekilmiştir. 
Tohum yüzey sterilizasyon işlemi bittikten sonra doku kültürü kabininde, bitki büyüme düzenleyicisi içermeyen MS besi ortamına tohumlar ekilmiştir. 2 gün karanlık ortamda, 8 gün iklim dolabında $25 \pm 2{ }^{\circ} \mathrm{C}$ 'de bekletildikten sonra bitkiler elde edilmiştir. bitki büyüme düzenleyicisi içeren her bir farklı konsantrasyon için üçer petri kullanılarak toplamda 30 tohum olacak şekilde, 3 tekrarlamalı yapılmıştır. Elde edilen bitkilerden hipokotil eksplantları alınarak farklı konsantrasyonlarda BAP $(187,5 \mu \mathrm{M}, 62,5 \mu \mathrm{M}, 12,5$ $\mu \mathrm{M})$ ve IAA $(12,5 \mu \mathrm{M}, 37,5 \mu \mathrm{M}, 62,5 \mu \mathrm{M})$ içeren besi ortamlarına ekimi yapılmış ve bitkilerin rejenere olduğu ideal besi ortamları ve bitki büyüme düzenleyicisi konsantrasyonları belirlenmiştir. Eksplant kaynağı olarak hipokotil kullanılmıştır. En ideal eksplant kaynağı ve besi ortamının araştırıldığı çalışmada, in vitro koşullarda bitki rejenerasyonu ve rejenerasyon yüzdeleri hesaplanmıştır.

\section{Bulgular ve Tartışma}

Tagetes minuta bitkisinde in vitro şartlarda bitki doku kültürü optimizasyonunu elde etmek amacıyla, tohumlar farklı oranlarda BAP ve IAA bitki büyüme düzenleyicileri içeren doku kültürü ortamlarında kültüre alınmıştır (Şekil 1-A, B). T. minuta bitkisi tohumları sodyum hipoklorit çözeltisinde $15 \mathrm{dk}$ ve \%70'lik etil alkolde 10 saniye tutularak steril edilebilmiştir. Kullanılan optimum sterilizasyon sonuçları Mohamed ve arkadaşları (1998) ve Modi ve arkadaşları (2009) tarafından yapılan çalışmaların sonuçları ile aynı değildir $[12,13]$. Aynı sterilizasyon koşullarının olmamasının birçok sebebi olabilir. Bunlardan bazıları; öncelikle genotiplerin farklı olması, alınan örneklerin birbirinden çok farklı coğrafyalardan alınması ve nemli ortamlardan alınan tohumlarda sterilizasyonda fazla kontaminasyonlarla karşılaşılması sayılabilir. Mesela; Mohamed ve arkadaşları (1998) kullandığı T. minuta bitkileri Meksika'dan toplanmıştır ve bu çalışmada kullanılan tohumlar ise Türkiye'den tedarik edilmiştir. in vitro şartlarda 
büyüyen bitkilerin hipokotili eksplant kaynağı olarak kullanılmıştır (Şekil 1-C-D). Bu eksplantlar sitokinin (BAP) ve oksin (IAA) bitki büyüme düzenleyicilerinin farklı konsantrasyonlarını $(187.5 \mu \mathrm{M}, 62.5 \mu \mathrm{M}, 12.5 \mu \mathrm{M})$ ve IAA $(12.5 \mu \mathrm{M}, 37.5 \mu \mathrm{M}, 62.5 \mu \mathrm{M})$ barındıran MS besiyerine ekilmiştir (1-E-H). Bitki eksplantları kallus (Şekil 1-G) oluşturmuştur ve rejenarasyon (Şekil 1-H) yüzdeleri kaydedilmiştir. Bitkiler daha sonra doğal ortamlarına ekilerek tekrar bitkiden elde edilen tohumlar toplanmıştır (Şekil-I-J). Elde edilen kallusların beyaz, yeşil, kahverengi gibi saf renklerde ya da bir kısmı yeşil diğer kısmı kahverengi olan çeşitli renklerde oldukları görülmüştür. BAP ve IAA bitki büyüme düzenleyicileri ve eksplantlar ile $T$. minuta kallus oluşumu ve morfolojisinin, Mohamed ve arkadaşları (1998), Sing ve arkdaşları (2016)' nın yaptığı çalışmalara benzerlik gösterdiği belirlenmiştir [14]. Yapılan istatistik analizleri sonucunda farklı bitki büyüme düzenleyicisi konsantrasyonlarının hipokotil eksplantına, in vitro rejenerasyonuna etkisi olduğu gözlenmiştir. En iyi kallus oluşturma yüzdesi 8 . uygulamada $(12.5 \mu \mathrm{M}$ BAP +37.5 IAA $\mu \mathrm{M}) \% 66$ orantyla belirlenirken, en iyi rejenerasyon yüzdesi ise 6 . uygulamada $(187.5 \mu \mathrm{M}$ BAP +37.5 IAA $\mu \mathrm{M}) \% 80,95$ oranıyla kaydedilmiştir (Tablo 1).

Tablo 1. Eksplantlardan elde edilen kalluslar ve kallusların rejenerasyon yüzdeleri

\begin{tabular}{|l|l|l|l|l|}
\hline Uygulama & BAP $(\boldsymbol{\mu M})$ & IAA $(\boldsymbol{\mu M})$ & $\begin{array}{c}\text { Kallus oranı } \\
(\boldsymbol{\%})\end{array}$ & $\begin{array}{c}\text { Rejenerasyon oranı } \\
(\boldsymbol{\%})\end{array}$ \\
\hline $\mathbf{1}$ & 187,5 & 12,5 & 33,3 & 66,6 \\
\hline $\mathbf{2}$ & 187,5 & 62,5 & 50 & 50 \\
\hline $\mathbf{3}$ & 187,5 & 37,5 & 36 & 64 \\
\hline $\mathbf{4}$ & 62,5 & 12,5 & 61,9 & 38,09 \\
\hline
\end{tabular}




\begin{tabular}{|l|l|l|l|l|}
\hline $\mathbf{5}$ & 62,5 & 62,5 & 62,5 & 37,5 \\
\hline $\mathbf{6}$ & 62,5 & 37,5 & 19,04 & 80,95 \\
\hline $\mathbf{7}$ & 12,5 & 12,5 & 50 & 50 \\
\hline $\mathbf{8}$ & 12,5 & 62,5 & 66,6 & 33,3 \\
\hline $\mathbf{9}$ & 12,5 & 37,5 & 50 & 50 \\
\hline
\end{tabular}

Rejeneratif kabiliyetin bitki büyüme düzenleyicilerin konsantrasyonlarının arttırılması ya da azaltılması ile değişmesinin nedenleri açıkça anlaşılamamıştır. Bu değişimin somaklonal değişiklikler ya da epigenetik faktörlerden kaynaklandığı düşünülmektedir. 


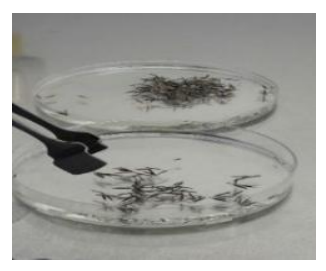

A
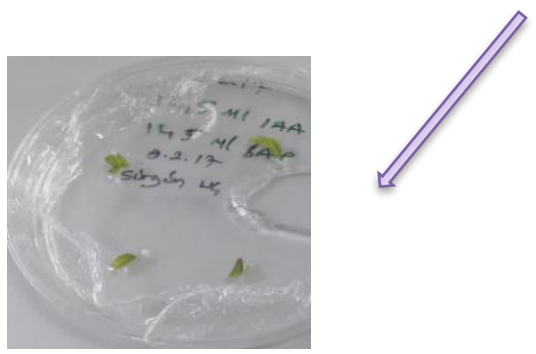

E

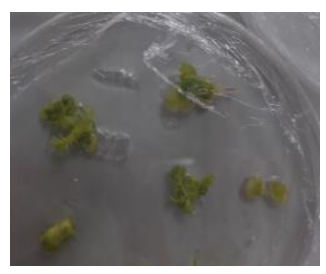

G

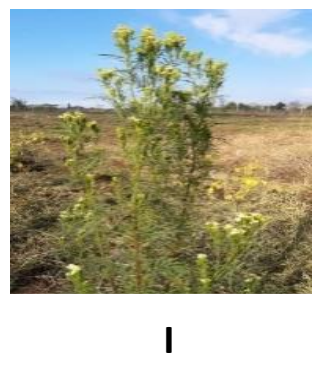

Şekil 1. T. minuta bitkisinin doku kültürü optimizasyonu

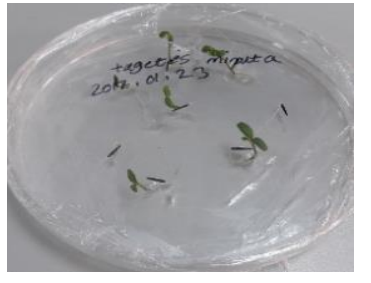

C

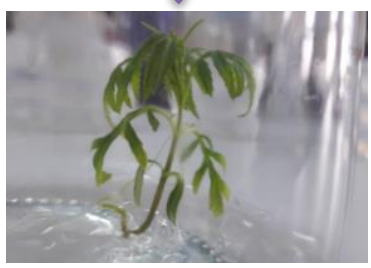

D

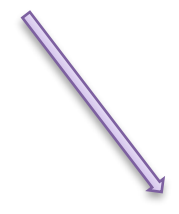

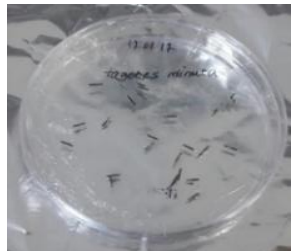

B
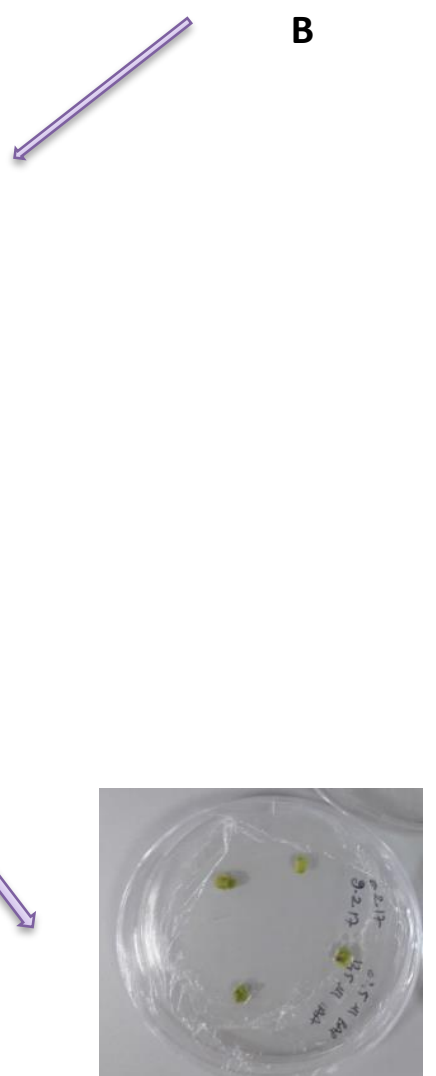

F

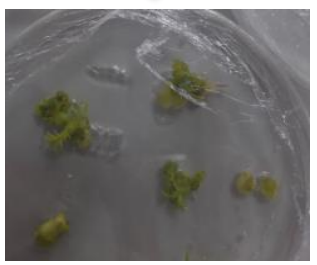

H

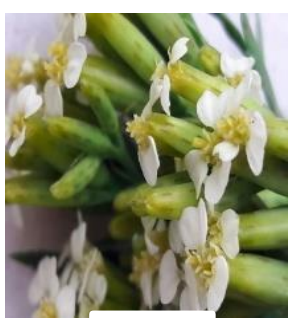

J 


\section{Sonuç}

Denemede kullanılan farklı konsantrasyonlardaki sitokinin ve oksin bitki büyüme düzenleyicilerini içeren ortamlarda T. minuta bitkisinin in vitro koşullardaki en başarılı kallus oluşumu \%66 oraniyla 8. Uygulamada (12.5 BAP $\mu \mathrm{M}+62.5$ IAA $\mu \mathrm{M})$ görülmüştür. En iyi rejenerasyon yüzdesi ise 6. uygulamada (62.5 BAP $\mu \mathrm{M}+37.5$ IAA $\mu \mathrm{M}) \% 80,95$ oranıyla kaydedilmiştir (Tablo 1). Rejenere olan bitkiler başarılı bir şekilde in vivo koşullarına aktarılmış ve iklimlendirilmiştir. Bu çalışmada geliştirilen in vitro doku kültürü optimizasyonu yöntemi, T. minuta bitkisi için gelecekte yapılması planlanan bitki biyoteknolojisi ve bitkilerin mikro çoğaltımı gibi yöntemlerin uygulanmasını olanaklı hale getirmektedir. Bu çalışmanın sonuçları, doğal yolla çoğalması zor olan bitkiler için alternatif bir çoğaltım yöntemi sunmuştur.

\section{Kaynaklar}

1. Sadia, S., et al., Tagetes minuta L., a useful underutilized plant of family Asteraceae: a review. Pakistan Journal of Weed Science Research, 2013. 19(2).

2. Uzabakiriho, A., O. Sinayobye, and S. Habimana, Antibacterial effects of Tagetes minuta plant extracts against Escherichia coli and Staphylococcus aureus in Rwanda. International Journal of Novel Research in Life Sciences, 2015. 2(2): p. 44-48.

3. Erdoğan, P., Kadife çiçeği (Tagetes erecta L.)'nin Tetranychus urticae Koch.(Acari: Tetranychidae)'ye karşı tuzak bitki olarak kullanımı. Akademik Ziraat Dergisi. 6: p. 109-114.

4. Köksal, N., S. Yasemin, and A. Özkaya, Kadife (Tagetes erecta) Bitkisinde Gün Uzunluğunun Büyüme ve Çiçeklenme Üzerine Etkisi. Turkish Journal of Agriculture: Food Science and Technology, 2017. 5(10): p. 1189-1193.

5. Arvas, Y.E., Genetiği Değişstirilmiş Bitkiler ve Tanısı. 2017: LAP Lambert Academic Publishing.

6. Kaya, Y. and S. Karakütük, Farklı büyüme düzenleyicilerin Türk kır çeltiği rejenerasyonuna etkisi. Anadolu Tarım Bilimleri Dergisi, 2018. 33(3): p. 226-231.

7. Sherkar, H. and A. Chavan, Studies on callus induction and shoot regeneration in tomato. Sci Res Rep, 2014. 1: p. 89-93.

8. Tütüncü, M., et al., in vitro haploidy techniques in ornamental plants. . Research Journal of Agricultural Sciences 2017. 10(1): : p. p.01-06.

9. Arvas, Y.E., et al. Karacağ Çeltiğine Biyoteknolojik Yaklaşımlar. in Uluslararası Diyarbakır Sempozyumu. 2016. Diyarbakır: Diyarbakır Valiliği. 
10. Kaya, Y., in vitro Plant Regeneration of Tobacco., in Faculty of Biosciences and Bioengineering. 2010, Universiti Teknologi Malaysia: Malaysia.

11. Kaya, Y., et al., Transformation of Nicotiana tabacum with dehE gene. Journal of Food Agriculture and Environment, 2013. 11(3-4).

12. Mohamed, M.-H., P. Harris, and J. Henderson, An efficient in vitro regeneration protocol for Tagetes minuta. Plant cell, tissue and organ culture, 1998. 55(3): p. 211-215.

13. Modi, P., A. Sinha, and S. Kothari, Reduction of hyperhydricity in micropropagated French marigold (Tagetes patula L.) plants by modified medium parameters. Floriculture and Ornamental Biotechnology, 2009. 3(1): p. 40-45.

14. Singh, P., et al., Chemistry and biology of industrial crop Tagetes Species: a review. Journal of EssEntial oil rEsEarch, 2016. 28(1): p. 1-14. 